\title{
La obra de Pere Rovira: diálogo entre géneros
}

\author{
Esther Martínez Borobio
}

Poeta, novelista y escritor de diarios; traductor y ensayista: la versatilidad creativa de Pere Rovira resulta incuestionable. Todos los géneros por él cultivados conforman una única voz y, a su vez, una voz única. Como vasos comunicantes, estos géneros dialogan entre sí y crean ese "personaje que se llama igual que el autor, que vive en la misma casa que él, que comparte sus amores, sus gustos, sus aversiones." (La finestra de Vermeer, 2016: 9).

El fragmento traducido pertenece al penúltimo dietario publicado por el autor; un dietario en el que Pere Rovira, además de reflexionar sobre la literatura, la muerte, el amor, la senectud, la enfermedad, el cine, la música y un sinfín de temas, nos regala nuevas traducciones, comparte lecturas e impresiones, cita sus propios versos y reproduce fragmentos de su primer dietario, Diari sense dies (1998-2003). Esta es, precisamente, la cuestión que queremos abordar en este artículo: el diálogo entre géneros y su imbricación en la conformación de una poética roviriana.

En el ensayo Los poemas necesarios, el profesor Rovira dedica un artículo a Diario de «Metropolitano» (1996: 95-99) de Carlos Barral. En este, nos presenta el dietario del poeta y editor barcelonés como un texto que documenta el proceso creativo: la planificación de los poemas, la labor de escritura y de revisión de los mismos; un "documento de primer orden" sobre la "disciplina literaria". Rovira, en sus clases, se servía de Diario de "Metropolitano» para comentar el poemario 19 figuras de mi historia civil: las notas del dietario se intercalaban con la lectura e interpretación de los poemas.

Los diarios de Pere Rovira no se detienen en cuestiones de creación, no nos adentran en el taller literario del poeta, pero sí permiten ese vaivén entre dietario y poesía, como si de un movimiento pendular se tratase; al leer sus novelas o sus dietarios, nos transporta a sus versos. 
Uno de los temas más importantes de la poética roviriana es, sin duda, su padre; tema que aparece ligado a la muerte, a la infancia y al recuerdo. En Diari sense dies, Rovira escribe el artículo "Diumenges", del que citamos un fragmento:

En la tristesa dels diumenges busco ara, després de tants anys, rastres d'aquell temps petit que va ser la nostra riquesa. (...) Em pregunto què devia sentir l'home jove que em donava la mà, com s'ho feia per no desesperar-se, per somriure, per no dir-me «no", quan jo volia que tornés a explicar-me per què corria més el cavall blanc. I em pregunto què hauria heretat si ell no hagués volgut regalar-me la seva joventut. (2004: 47)

Este fragmento del artículo publicado en el periódico Avui y recogido en el compendio Diari sense dies tiene su correspondencia poética en La mar de dins, poemario dedicado a sus progenitores y ganador del Premi Carles Riba en 2002. El plural utilizado en todos los títulos de los artículos periodísticos, excepto en tres, "El mestre", "For ever Young (En la mort de Jordi Jové)" y "Clar i difícil”, cede paso al singular, "El diumenge", en La mar de dins. Sin embargo, ambos textos tratan un mismo tema:

Pare enterrat, que m'acompanyes

pel temps que torna, cap al final,

amb un mort jove $\mathrm{i}$ amb un nen mort

que no sabran res de nosaltres.

Ja els sento viure: l'home dibuixa

un cavall blanc; la meva mà

dins de la seva vol un diumenge

que no s'acabi. (...) (Poesia. 1979-2004, 2006: 147)

Además, en La finestra de Vermeer, podemos seguir el proceso de publicación de Les guerres del pare, novela que recrea e inventa historias sobre su padre. Se deja constancia de la revisión de las galeradas de la novela, de su llegada a las librerías, de la presentación de la misma, de las primeras reseńas críticas... pero también se reflexiona sobre su propósito, sobre cómo la van a leer y cómo la leen las personas más allegadas — su madre y su hermana—, y sobre la posible aceptación del público: "Surt a les llibreries Les guerres del pare. El llibre ja és a la seva guerra. Fins avui, només havia trobat aliats; ara trobarà adversaris. Però els llibres necessiten lectors, no els cal res més." (2016: 212). Junto a estos temas, los recuerdos en compañía de su padre: los días de caza, los de la terraza cerca del "balcó del Mediterrani", los de los chistes y los de la víspera de "Sant Pere".

En una entrada del jueves 3 de octubre, Rovira explica que su madre guarda cartas de amor escritas por su padre. Dice así:

He tractat d'imaginar-me-la, sola, a casa, traient les cartes del seu amagatall, escampant-les sobre la tauleta de la sala i llegint-les a poc a poc, amb les paraules tremolantli a la boca i els ulls humits. Cartes que tenen més de setanta anys, amb una joventut que ha resistit tota una vida que ja s'acaba. (2016: 364) 
El fragmento nos lleva al artículo "Cartes", de Diari sense dies. Ambos textos se centran en una temática común y esto posibilita la conexión; se actualizan:

Però hi ha milers i milers de cartes desconegudes que potser han emocionat més que aquestes. Cartes de mares, de condemnats, de malaltes, cartes que venien de la guerra, o de la mar, o d'una mina, cartes de por, de venjança, d'alegria... Un catàleg immens dels sentiments dels segles, perdut, oblidat.

No del tot: ¿Qui pot estar segur que no deu res a cap pobre paper atapeït de mala cal.ligrafia? ¿Quants de nosaltres vivim perquè una nit, fa cent hiverns, un home que estava molt cansat va encendre una espelma i va començar a escriure una carta? (2004: 13)

Más fácil es el caso siguiente, donde el mismo autor es quien nos da las pistas para la lectura: en la entrada del 28 de junio, vigilia de su onomástica, Rovira explica sus planes para el día siguiente de visitar la tumba de su padre y llevarle tres rosas rojas. Inmediatamente después, cita los cuatro primeros versos del poema "Sant Pere", incluido en Contra la mort, donde explica este ritual. Pere Rovira tan solo transcribe la primera estrofa, cuyo verso final coincide con el título del poemario; sin embargo, lejos de la simple anotación, estos nos trasladan al poema y a sus contundentes versos finales: "Pare, cada any ets més en el meu pols/ i els cops de no tenir-te són més forts” (2011:71). Y es que la propia muerte se siente como próxima, y se convierte en tema recurrente en las páginas del dietario. "Sé que finalment me n’hauré d'anar." (2016: 512), sentencia en la última página.

El segundo de los temas que vertebran toda la obra roviriana es el amor. La finestra... no solo es un espacio de reflexión acerca del enamoramiento o sobre las edades del amor; el amor es una constante, pues se respira en las anotaciones sobre sus seres queridos, ya desde las dedicatorias que abren el dietario.

Desde el punto de vista literario, La finestra... nos invita a retomar otro poemario, Distàncies (1981), cuya historia contada en él cumple treinta y cuatro años: "Avui fa trenta-quatre anys que vam començar a estar junts. El matí d'aquell 16 de gener semblava que era només el final d'una nit, però era el començament d'una vida" (2016: 44), "vida" narrada en el día a día de las páginas de La finestra... y sobre la que también reflexiona:

La soledat d'ara, tan facil, tan volguda, se'm faria, en canvi insuportable si la Celina no hi fos. Aquest és el pensament més terrible que puc tenir: quedar-me sense ella. I tant és així, que el que m’aterreix més de la meva mort és perdre-la a ella per sempre. Perdre la nostra vida, tan simple, tan monòtona, tan plena. Les monotonies de l'amor satisfet, divertit, plaent, descansat, ¿quina altra glòria podria voler? (2016: 352).

Distàncies aparece en el dietario de forma explícita gracias a la efeméride de un poema, "17 de maig", o motivado por una conversación acerca del texto en prosa "Temps". En el prólogo a Poesia y acerca de este poemario escrito en 1981, Pere Rovira escribe: 
“... m'estimo aquest llibre perquè parla del millor regal que la poesia m’ha fet: un amor que no havia de durar i que, tal com estan les coses, és probable que duri més que jo." (2006: 11).

Esta es, precisamente, una idea que encontramos en "El darrer estiu" de La mar de dins: "El nostre sempre, l'únic que ens importa, / durarà més que jo." (2003: 59); "Sempre" es el título de un poema y de una sección de Contra la mort. De hecho, el poemario hace hincapié en el tópico del amor post mortem. Ya en el primer poema que abre el libro se plantea la situación de la separación de los amantes: "Jo, a l'altre costat de la frontera fosca; tu, dintre de la vida" (2011: 15). El poemario se va construyendo como un mensaje a su esposa. En "Dedicatòria", haciendo referencia al libro que tenemos entre las manos, subraya: "No és un últim adéu: / ha jugat contra els daus de la mort, / (...) i, com jo quan l'escric, fa el cor fort:/ vol durar, per estar més amb tu." (2011: 61). Por último, los versos que cierran el volumen insisten en esa idea del amor más allá de la muerte: "el meu amor no entén la paraula morir; / per estimar-te sempre, no em necessita a mi." (2011: 115)

Finalmente, vamos a detenernos en el tercero de los temas recurrentes en la obra de Pere Rovira: la literatura.

En La finestra..., se dan cita distintos textos: versos propios y ajenos, traducciones, fragmentos de lecturas y de sus propios textos. Cabe destacar que Rovira utiliza anotaciones de Diari sense dies o de su poesía (propia o traducida) para la preparación de conferencias y, gracias al dietario, tenemos acceso a los borradores o a los esbozos de estas: la que trata sobre el retrato y sus lenguajes, la del curso "Poesia per a narradors" y la dedicada a Baudelaire para el ciclo "El meu clàssic".

La finestra... también vuelve la mirada atrás y reflexiona, con dureza, sobre la llamada "poesía de la experiencia", una poesía de la que participó a finales de los ańos ochenta y principios de los noventa. De nuevo, Rovira nos regala la guía de lectura para un poema de Contra la mort titulado "Amics vells", y explica que, para su construcción, utilizó la retórica "de entonces". Sus "compańeros de viaje”, como diría Gil de Biedma, de la "poesía de la experiencia" también tienen cabida en el dietario; se mencionan Felipe Benítez Reyes, Luis García Montero, Javier Egea, Carlos Marzal y Vicente Gallego.

Por su parte, Diari sense dies recoge ochenta y un artículos publicados en el rotativo Avui entre 1998 y 2003. Cada uno de ellos está dedicado a un tema que se presenta como universal, y de ahí el plural de sus títulos. Además, todos ellos contienen al menos una cita literaria que sirve de pretexto para o bien ampliar una idea o bien debatirla, estableciéndose, así, un diálogo. Precisamente, en "Diàlegs", Rovira escribe: "Les biblioteques mentals dels escriptors, com deia Auden, estan molt desordenades. O potser tenen l'ordre més convenient, el de la necessitat, la passió i l'interès". (2004: 42). Las obras de Rovira abren las puertas a esa biblioteca mental del autor: nos permiten conocer sus referentes y subrayan versos memorables.

Luis García Montero, en un artículo titulado "El arte de leer versos", recogido en el homenaje de Litoral a Jaime Gil de Biedma, explicaba las fórmulas que el poeta barcelonés utilizaba para "convertir la poesía en una operación de lectura". Los procedimientos 
mencionados pueden encontrarse también en la obra de Pere Rovira, no solo en su producción poética, sino también en las obras en prosa: el primero de ellos es el que utiliza la cita de un clásico; esta se coloca al inicio y en el interior del poema. "Guiomar", de $\mathrm{La}$ mar de dins, es un ejemplo de esta fórmula; el poema se abre con la cita del primer verso del poema LXXVII de Poesias de guerra de Antonio Machado: "De mar a mar entre los dos la guerra”. Rovira lo utiliza para plantear la situación del poema y dar voz, no solo a Machado, al reescribir algunas ideas del poema original, sino a Guiomar.

El segundo procedimiento es aquel en el que se cita a un autor como si se tratase de una conversación entre amigos o eludiendo el nombre del autor. Un ejemplo procedente de Diari sense dies y que evoca a Stendhal sería: "Ens enamorem perquè llegim novel.les, va dir algú que coneixia molt bé les novel.les i els enamoraments." (2004: 14)

El tercer procedimiento se sirve de versos enteros, tanto literales como modificados, que se insertan en el propio poema; el eco de los primeros versos de "Lo fatal" de Rubén Darío se escucha en "El llorer": "A penes sensitiu, feliç ignora/ l'arbre que serà foc, fum i passat" (2011: 39). Aquí podríamos incluir las citas de fragmentos procedentes de textos en prosa; es el caso de esta clara alusión a Bécquer: "hi ha una altra durada que és difícil de mesurar i que és més decisiva: la que es produeix dins de cada lector, l'efecte que continua quan la peça ja s'ha acabat i queda només la vibració íntima de les cordes". (2004: 43).

El último procedimiento es el que utiliza citas de su propia obra. Precisamente, a lo largo de estas líneas, hemos querido acercar algunos fragmentos que dialogaban entre sí, que poetizaban una misma cuestión. De este modo, la obra de Pere Rovira puede leerse como un único texto que encuentra en los distintos géneros el vehículo para conformar esa voz tan singular que la hace inconfundible.

\section{BibliografíA}

García Montero, Luis (1986). "El arte de leer versos” en Litoral. Jaime Gil de Biedma. El juego de hacer versos. Números 163-165. Málaga.

Rovira, Pere (1996). Los poemas necesarios. Estudios y notas sobre la poesía del medio siglo. Servicio de publicaciones de la Universidad de las Islas Baleares. Palma de Mallorca. (2003). La mar de dins. Proa, Barcelona. (2004). Diari sense dies. (1998-2003). Proa, Barcelona. (2006). Poesia. 1979-2004. Proa, Barcelona. (2011). Contra la mort. Proa, Barcelona. (2016). La finestra de Vermeer. Un dietari. Proa, Barcelona. 